\title{
Elevated preoperative neutrophil-to-lymphocyte ratio as a predictor of worse survival after resection in patients with brain metastasis
}

\author{
Koichi Mitsuya, MD, PhD, ${ }^{1}$ Yoko Nakasu, MD, PhD, ${ }^{1}$ Takeshi Kurakane, ${ }^{3}$ \\ Nakamasa Hayashi, MD, PhD, ${ }^{1}$ Hideyuki Harada, MD, PhD, ${ }^{2}$ and Kazuhiko Nozaki, MD, PhD ${ }^{3}$ \\ Divisions of ${ }^{1}$ Neurosurgery and ${ }^{2}$ Radiation Oncology, Shizuoka Cancer Center, Shizuoka; and ${ }^{3}$ Department of Neurosurgery, \\ Shiga University of Medical Science, Otsu, Japan
}

\begin{abstract}
OBJECTIVE The median postoperative survival duration of patients with brain metastases who undergo tumor resection is 12 months. Most of these patients die of systemic metastases or the progression of primary cancer but not brain metastases. The criteria for indicating resection are still controversial. Systemic assessment is restricted, especially in patients who need emergent management for their large-size or life-threatening brain metastases. The neutrophil-tolymphocyte ratio (NLR) is reported to correlate with survival time or progression-free survival in patients with various cancers. However, NLR has not been assessed in patients with brain metastases. The impact of NLR on the survival data of patients who had undergone resection of brain metastases was retrospectively analyzed.
\end{abstract}

METHODS The clinical records of patients who underwent resection of brain metastases at Shizuoka Cancer Center between May 2007 and January 2015 were retrospectively analyzed. NLR was calculated by using the data obtained from the latest examination before resection and before the administration of steroid therapy. Kaplan-Meier curves were used for the assessment of overall survival (OS).

RESULTS Of the 105 patients included, 67 patients were male. The median age of the patients was 63 years (range 36-90 years). The primary cancers were lung, colon, breast, uterus, and other cancers in 48, 19, 10, 8, and 20 patients, respectively. The postresection median survival duration was 12 months (range 1-91 months) for the entire series. The optimum NLR threshold value was identified as 5 . A significant difference in the median OS was found: 14 months for 82 patients with an NLR $<5$ versus 5 months for 23 patients with an NLR $\geq 5(p=0.001)$.

CONCLUSIONS In this study, an elevated preoperative NLR is a predictor of worse survival after resection for brain metastases. NLR is a simple, systemic marker and can be used in clinical settings for decision making regarding resection in patients with brain metastases.

https://thejns.org/doi/abs/10.3171/2016.8.JNS16899

KEY WORDS metastatic brain tumor; neutrophil-to-lymphocyte ratio; prognostic factor; surgery; oncology

$\mathrm{B}$ RAIN metastases occur in $10 \%$ to $40 \%$ of patients with cancer and are the most common central nervous system neoplasm in adults. ${ }^{28,33}$ With increased surveillance, improved control of systemic cancer, and prolonged survival, the incidence of patients with brain metastases is increasing. ${ }^{17}$ The management of brain metastases has been revolutionized in clinical oncology by 4 developments: improved brain imaging, improved management of systemic diseases, the distribution of stereo- tactic irradiation, and the extension of less invasive surgical techniques that enable brain metastases to be removed even from eloquent brain areas with minimal morbidity. ${ }^{5}$ Although stereotactic irradiation and pharmacotherapies contribute to the treatment outcome of patients with brain metastasis, resection is still a mainstay for large brain metastases.

The indications for resection include a symptomatic mass, a mass with considerable edema requiring high-dose

ABBREVIATIONS DS-GPA = diagnosis-specific graded prognostic assessment; KPS = Karnofsky Performance Status; NLR = neutrophil-to-lymphocyte ratio; OS = overall survival; RPA = recursive partitioning analysis.

SUBMITTED April 11, 2016. ACCEPTED August 24, 2016.

INCLUDE WHEN CITING Published online December 2, 2016; DOI: 10.3171/2016.8.JNS16899. 
steroids, a mass greater than $3 \mathrm{~cm}$, and a mass with an unknown primary cancer. ${ }^{5}$ In addition, an estimated life expectancy of more than 3 or 6 months is a factor used to indicate a candidate for resection. Patients in the terminal stage may receive neither a survival benefit nor an improvement in their quality of life from invasive treatments.

Several studies have attempted to identify prognostic factors and predict the life expectancy of patients with brain metastases, and classification systems including recursive partitioning analysis (RPA) classification and diagnosis-specific graded prognostic assessment (DS-GPA) have been developed. 9,29 These classification systems have been mainly validated in patient populations treated with radiotherapy. ${ }^{1,6,10} \mathrm{~A}$ simple and reliable marker that reflects the systemic conditions of patients with brain metastases is needed in the decision-making process for resection. . $^{21,23,26,31}$

Interest in the host inflammatory response to neoplasms is increasing. Inflammatory cells accumulating around cancer cells play an important role in the prognosis of patients. Patients with lymphocyte infiltration around the tumor may have a better prognosis than those without infiltration, and patients with neutrophils infiltrating around their cancers may be associated with a poor prognosis..$^{15,35}$ A systematic inflammatory response leads to changes in the relative levels of circulating white blood cells, resulting in an increase in neutrophils and a decrease in lymphocytes with the progression of cancer. ${ }^{25}$ Recently, an association was reported between a high neutrophil-to-lymphocyte ratio (NLR) and shorter survival time in patients with various cancers, ${ }^{4,8,11,13,14,16,19,22,27,34}$ including glioblastoma. ${ }^{3,12,18}$ However, the value of preoperative NLR in the assessment of candidates for resection for brain metastasis has not been evaluated.

The aim of this study was to retrospectively evaluate outcomes and prognostic factors, including NLR, in patients with brain metastases who underwent resection. We hypothesized that preoperative NLR contributes to identifying patients likely to benefit from resection.

\section{Methods \\ Patient Population}

We retrospectively studied patients who underwent resection as their first surgery for brain metastases with complete laboratory data available at Shizuoka Cancer Center between May 2007 and January 2015. All patients were diagnosed with brain metastases using MRI and had a histologically proven metastatic tumor in the brain. No patient underwent pre- and postoperative immunotherapy.

The patients' clinical data included their age, sex, primary cancer, and Karnofsky Performance Status (KPS). Data from routine laboratory measurements were recorded to determine complete blood counts with differential leukocyte counts. Blood sampling was performed 1 to 14 days before surgery and under conditions without steroid therapy. NLR was calculated by dividing the absolute neutrophil count by the absolute lymphocyte count. The RPA class and DS-GPA score of each patient were estimated using published criteria. ${ }^{9}$ The institutional review board approved the analysis in this study.

\section{Treatment}

Our cancer board approved resection for patients with the following characteristics: 1) a postsurgery life expectancy of 6 months or longer based on information from medical oncologists; 2) single metastases measuring more than $3 \mathrm{~cm}$, or multiple or smaller tumors associated with serious symptoms that were expected to improve with resection; and 3) no clinical manifestations or radiological findings indicating leptomeningeal metastasis. Resection with a safety margin or enucleation was applied as neurosurgical techniques depending on the eloquence and border zone pathology. ${ }^{20}$ In principle, adjuvant radiotherapy usually began 1 to 2 weeks after surgery. Adjuvant stereotactic radiotherapy was used only for patients with a surgical remnant or unresected lesions. After brain metastases were controlled, the patients received further systemic therapy or best supportive care according to decisions made by the medical oncologists. In patients who had tumor recurrence after radiotherapy, the indication for salvage treatment was judged via discussion at our cancer board with senior radiation oncologists. Nineteen patients (18\%) underwent salvage resection after radiotherapy.

\section{Statistical Analyses}

Overall survival (OS) time was calculated from the date of the first resection for brain metastases to the date of death due to any cause. The statistical analysis was performed using JMP (version 11; SAS Institute). The data for survival time were analyzed using the Kaplan-Meier method. Values were compared using the log-rank test. Frequency analysis was performed using the Fisher exact test. A p value $<0.05$ was considered statistically significant.

\section{Results}

The characteristics of all patients are shown in Table 1. Sixty-three patients were male, and the median age of the patients was 63 years (range 36-90 years). The primary cancers were lung, colon, breast, uterus, stomach, esophagus, kidney, thyroid, ovary, and other cancers in 48, 19, 10 , $8,4,3,3,2,2$, and 6 patients, respectively. Other cancers included pharyngeal, mandibular, cholangic, vaginal, and bladder cancer and leiomyosarcoma. After surgery, adjuvant radiation therapy was administered. Thirteen patients received local radiation therapy or stereotactic irradiation, and 72 patients received whole-brain RT. Table 2 reports the adjuvant radiotherapy and systemic chemotherapy administered to our cohort. Patients with an NLR $<5$ underwent chemotherapy significantly more frequently than patients with an NLR $\geq 5$. The median survival time of all the cohorts was 12 months (range 1-91 months). The median NLR prior to surgery was 2.91 (mean 4.19; range 1.0-20.0; 95\% CI 3.5-4.86). The receiver operating characteristic curve showed a cutoff value of 5.0 as a marker of more than 6 months of survival with a sensitivity of $87.0 \%$ and specificity of $46.4 \%$. The area under the curve was 0.704 (Fig. 1). We set the optimum NLR threshold value as 5, as in previous reports of other cancers. ${ }^{34}$ Of 105 patients, 82 (78\%) patients had an NLR of $<5$. The median OS after resection in the patients with an NLR of $<5$ was 14 months, 
TABLE 1. Patient characteristics and NLR

\begin{tabular}{|c|c|c|c|}
\hline \multirow[b]{2}{*}{ Variable } & \multicolumn{3}{|c|}{ No. of Patients (\%) } \\
\hline & All Patients & $N L R<5$ & $N L R \geq 5$ \\
\hline No. of patients & 105 & 82 & 23 \\
\hline \multicolumn{4}{|l|}{ Sex } \\
\hline Male & $67(64)$ & $48(59)$ & $19(83)$ \\
\hline Female & $38(36)$ & $34(41)$ & $4(17)$ \\
\hline \multicolumn{4}{|l|}{ Age in yrs } \\
\hline$<65$ & $58(55)$ & $43(52)$ & $15(65)$ \\
\hline$\geq 65$ & $47(45)$ & $39(48)$ & $8(35)$ \\
\hline \multicolumn{4}{|l|}{ KPS } \\
\hline $90-100$ & $9(9)$ & $7(9)$ & $2(8)$ \\
\hline $70-80$ & $37(35)$ & $32(39)$ & $5(22)$ \\
\hline $50-60$ & $49(46)$ & $38(46)$ & $11(48)$ \\
\hline 40 & $10(10)$ & $5(6)$ & $5(22)$ \\
\hline \multicolumn{4}{|l|}{ Primary cancer } \\
\hline Lung & 48 & 37 & 11 \\
\hline Colon & 19 & 15 & 4 \\
\hline Breast & 10 & 10 & 0 \\
\hline Uterus* & $8^{*}$ & 6 & 2 \\
\hline Stomach & 4 & 3 & 1 \\
\hline Esophagus & 3 & 2 & 1 \\
\hline Kidney & 3 & 3 & 0 \\
\hline Thyroid* & $2^{*}$ & 1 & 1 \\
\hline Ovary* & $2^{*}$ & 2 & 0 \\
\hline Other* & $6^{*}$ & 3 & 3 \\
\hline \multicolumn{4}{|c|}{ RPA classification } \\
\hline Class 1 & $9(9)$ & $8(10)$ & $1(4)$ \\
\hline Class 2 & $37(35)$ & $31(38)$ & $6(26)$ \\
\hline Class 3 & $59(56)$ & $43(52)$ & $16(70)$ \\
\hline
\end{tabular}

* Patients with brain metastases from cancers not listed in DS-GPA.

and the median OS of those with an NLR of $\geq 5$ was 5 months ( $\mathrm{p}=0.01$ according to the log-rank test; Fig. 2 ).

\section{Discussion}

Brain metastases are no longer considered a single entity but a special site of metastatic cancer; they are assessed

\section{TABLE 2. Postoperative treatment and NLR}

\begin{tabular}{lllr}
\hline \multicolumn{1}{c}{ Variable } & $\begin{array}{c}\text { All } \\
\text { Patients }\end{array}$ & $\begin{array}{c}\text { NLR } \\
<5\end{array}$ & $\begin{array}{c}\text { NLR } \\
\geq 5\end{array}$ \\
\hline No. of patients & 105 & 82 & 23 \\
\hline Radiotherapy after surgery (\%) & & & \\
\hline Whole brain & $72(69)$ & $56(68)$ & $16(70)$ \\
\hline Local & $13(12)$ & $10(12)$ & $3(13)$ \\
\hline None & $20(19)$ & $16(20)$ & $4(17)$ \\
\hline Systemic therapy after surgery (\%) & & & \\
\hline$\quad$ Chemotherapy & $49(47)$ & $45(55)$ & $4(17)$ \\
\hline$\quad$ No chemotherapy & $40(38)$ & $24(29)$ & $16(70)$ \\
\hline$\quad$ Not needed (no extracranial metastasis) & $16(15)$ & $13(16)$ & $3(13)$ \\
\hline
\end{tabular}

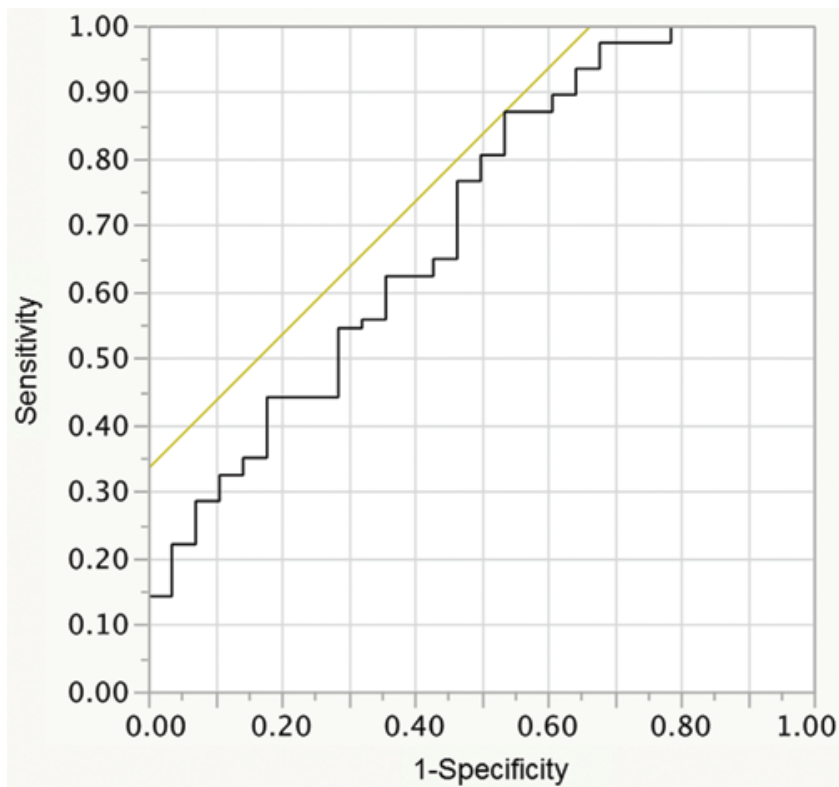

FIG. 1. Receiver operating characteristic curve showing an area under the curve of 0.704 .

and managed in the context of the primary cancer and the patient's overall systemic options. Treatment is multidisciplinary and individualized. Resection is important in the management of patients with brain metastases. Patients with obstructive hydrocephalus, large or cystic tumors, tumors with mass effect or marked edema, or neurological deficits despite steroid therapy are best treated with craniotomy and resection of the brain metastases. ${ }^{5}$

The decision to perform resection in each patient must be made urgently but cautiously because surgery has a potential concern for morbidity and mortality. The selection criteria should include both the patient's whole systemic condition and the characteristics of the brain metastases. Despite successful resection, a certain number of patients

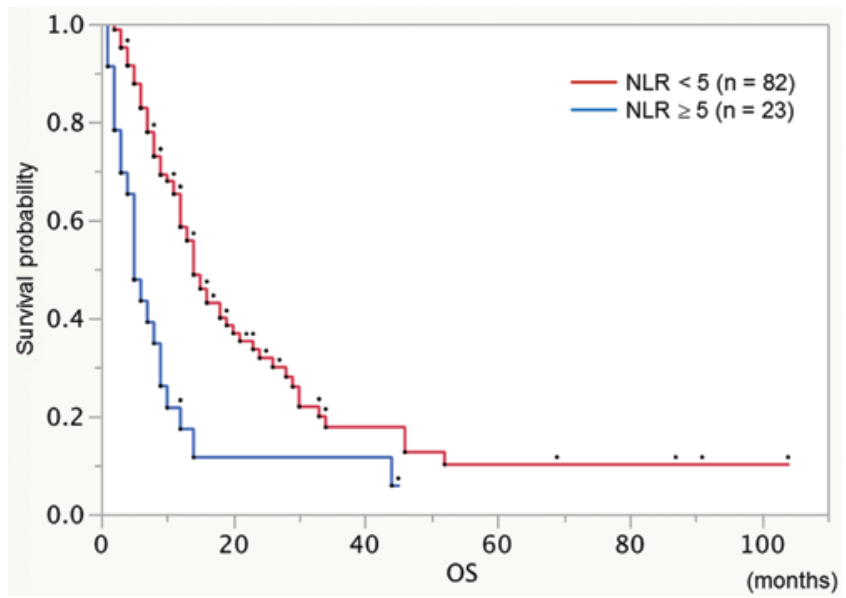

FIG. 2. Kaplan-Meier survival curves for the patients with a high preoperative NLR $(\geq 5)$ in comparison with those patients with a low preoperative NLR $(<5)$. The median OS of the patients with a high NLR is 5 months, whereas that of the patients with a low NLR is 14 months. 
die within a short postoperative period as a result of rapid systemic tumor progression or an impaired general condition. ${ }^{2}$ The survival of patients with advanced cancer is linked to a complex interplay of disease progression, performance status, inflammatory status, cachexia, and other factors. ${ }^{30}$

NLR is simple and easy to calculate using routine laboratory data without an additional technique or cost. The results of this study indicated that elevated NLR was a clear clinical predictor of poor outcome in patients who underwent resection for brain metastases. Consistent with previous studies of advanced cancers, elevated NLR was a strong prognostic factor. $4,8,11,13,14,16,19,22,27,34$

The role of the host inflammatory response in determining tumor spread is increasingly recognized. The association between elevated NLR and poor prognosis has several possible explanations. An elevated NLR may be a consequence of more neutrophils, fewer lymphocytes, or both. Cancers are known to release myeloid growth factors, and this subsequently leads to the increased production of neutrophils. ${ }^{32}$ Meanwhile, circulating neutrophils have been shown to contain and secrete vascular endothelial growth factor, tumor necrosis factor, and other cytokines that contribute to cancer progression. Therefore, an elevated neutrophil count stimulates tumor angiogenesis and aids in the proliferation of neoplasms. This vicious cycle may lead to the poor outcome of affected patients. ${ }^{30}$ Another possible explanation is that patients with an elevated NLR have lymphocytopenia and decreased lymphocyte function. An increased level of neutrophils suppresses the cytolytic activity of lymphocytes, natural killer cells, and activated T cells. 7,24

Since the Radiation Therapy Oncology Group performed an RPA for the prediction of survival in the late 1990s, several assessment systems have provided information on individual prognosis. The RPA classification is a simple method for predicting outcome based on KPS, age, primary tumor control, and extracranial metastasis. ${ }^{9} \mathrm{RPA}$ can be applied to any kind of primary cancer. RPA sometimes cannot separate Class 2 cases from Class 3 cases with the same low KPS by their neurological deficits, especially in patients with large brain metastases. Our study showed that the Kaplan-Meier curves of the RPA Class 2 and Class 3 patients were nearly identical, as previously reported..$^{31}$ DS-GPA is a refined new system for the prediction of survival time in patients with brain metastases from lung cancer, breast cancer, melanoma, gastrointestinal tract cancers, and renal cell carcinoma. However, DSGPA cannot be applied to patients with brain metastases from cancers not listed in DS-GPA, which are not rare and accounted for $17 \%$ of the patients in our study (Table 1). DS-GPA also has the same problem as RPA classification in the estimation of lower KPS. Therefore, we recommend including NLR in the systemic assessment process for resection candidates.

There are 3 limitations of this study. 1) Neutrophilia is sometimes nonspecific, and the sensitivity is good but the specificity is moderately low. When subclinical infection occurs, neutrophils are often dominant. 2) During corticosteroid treatment, neutrophilia is occasionally observed, and we excluded data during corticosteroid prescription. 3) Acute stress could increase the number of neutrophils.

\section{Conclusions}

In our study, elevated preoperative NLR is a predictor of worse survival after resection for brain metastases. Further research will be needed to understand the interaction of brain metastases and immunological environments. The future refinement of the prognostic markers of brain metastases will identify a population of patients likely to benefit from surgical intervention.

\section{References}

1. Agboola O, Benoit B, Cross P, Da Silva V, Esche B, Lesiuk $\mathrm{H}$, et al: Prognostic factors derived from recursive partition analysis (RPA) of Radiation Therapy Oncology Group (RTOG) brain metastases trials applied to surgically resected and irradiated brain metastatic cases. Int J Radiat Oncol Biol Phys 42:155-159, 1998

2. Arita H, Narita Y, Miyakita Y, Ohno M, Sumi M, Shibui S: Risk factors for early death after surgery in patients with brain metastases: reevaluation of the indications for and role of surgery. J Neurooncol 116:145-152, 2014

3. Bambury RM, Teo MY, Power DG, Yusuf A, Murray S, Battley JE, et al: The association of pre-treatment neutrophil to lymphocyte ratio with overall survival in patients with glioblastoma multiforme. J Neurooncol 114:149-154, 2013

4. Bhatti I, Peacock O, Lloyd G, Larvin M, Hall RI: Preoperative hematologic markers as independent predictors of prognosis in resected pancreatic ductal adenocarcinoma: neutrophil-lymphocyte versus platelet-lymphocyte ratio. Am J Surg 200:197-203, 2010

5. Black PM, Johnson MD: Surgical resection for patients with solid brain metastases: current status. J Neurooncol 69:119124, 2004

6. Chidel MA, Suh JH, Reddy CA, Chao ST, Lundbeck MF, Barnett GH: Application of recursive partitioning analysis and evaluation of the use of whole brain radiation among patients treated with stereotactic radiosurgery for newly diagnosed brain metastases. Int J Radiat Oncol Biol Phys 47:993-999, 2000

7. el-Hag A, Clark RA: Immunosuppression by activated human neutrophils. Dependence on the myeloperoxidase system. J Immunol 139:2406-2413, 1987

8. Garcea G, Ladwa N, Neal CP, Metcalfe MS, Dennison AR, Berry DP: Preoperative neutrophil-to-lymphocyte ratio (NLR) is associated with reduced disease-free survival following curative resection of pancreatic adenocarcinoma. World J Surg 35:868-872, 2011

9. Gaspar L, Scott C, Rotman M, Asbell S, Phillips T, Wasserman T, et al: Recursive partitioning analysis (RPA) of prognostic factors in three Radiation Therapy Oncology Group (RTOG) brain metastases trials. Int J Radiat Oncol Biol Phys 37:745-751, 1997

10. Golden DW, Lamborn KR, McDermott MW, Kunwar S, Wara WM, Nakamura JL, et al: Prognostic factors and grading systems for overall survival in patients treated with radiosurgery for brain metastases: variation by primary site. $\mathbf{J}$ Neurosurg 109 Suppl:77-86, 2008

11. Gomez D, Farid S, Malik HZ, Young AL, Toogood GJ, Lodge JP, et al: Preoperative neutrophil-to-lymphocyte ratio as a prognostic predictor after curative resection for hepatocellular carcinoma. World J Surg 32:1757-1762, 2008

12. Han S, Liu Y, Li Q, Li Z, Hou H, Wu A: Pre-treatment neutrophil-to-lymphocyte ratio is associated with neutrophil and T-cell infiltration and predicts clinical outcome in patients with glioblastoma. BMC Cancer 15:617, 2015

13. Jung MR, Park YK, Jeong O, Seon JW, Ryu SY, Kim DY, et al: Elevated preoperative neutrophil to lymphocyte ratio pre- 
dicts poor survival following resection in late stage gastric cancer. J Surg Oncol 104:504-510, 2011

14. Kang MH, Go SI, Song HN, Lee A, Kim SH, Kang JH, et al: The prognostic impact of the neutrophil-to-lymphocyte ratio in patients with small-cell lung cancer. Br J Cancer 111:452-460, 2014

15. Kawata A, Une Y, Hosokawa M, Uchino J, Kobayashi H: Tumor-infiltrating lymphocytes and prognosis of hepatocellular carcinoma. Jpn J Clin Oncol 22:256-263, 1992

16. Kishi Y, Kopetz S, Chun YS, Palavecino M, Abdalla EK, Vauthey JN: Blood neutrophil-to-lymphocyte ratio predicts survival in patients with colorectal liver metastases treated with systemic chemotherapy. Ann Surg Oncol 16:614-622, 2009

17. Lin X, DeAngelis LM: Treatment of brain metastases. J Clin Oncol 33:3475-3484, 2015

18. McNamara MG, Lwin Z, Jiang H, Templeton AJ, Zadeh G, Bernstein M, et al: Factors impacting survival following second surgery in patients with glioblastoma in the temozolomide treatment era, incorporating neutrophil/lymphocyte ratio and time to first progression. J Neurooncol 117:147-152, 2014

19. Nakano K, Hosoda M, Yamamoto M, Yamashita H: Prognostic significance of pre-treatment neutrophil: lymphocyte ratio in Japanese patients with breast cancer. Anticancer Res 34:3819-3824, 2014

20. Nakasu Y, Mitsuya K, Hayashi N, Ito I: [Two surgical techniques for metastatic brain tumors: minimum resection and removal with safety margin.] No Shinkei Geka 44:221-226, 2016 (Jpn)

21. Nieder C, Astner ST, Andratschke NH, Marienhagen K: Postoperative treatment and prognosis of patients with resected single brain metastasis: how useful are established prognostic scores? Clin Neurol Neurosurg 113:98-103, 2011

22. Okamura Y, Ashida R, Ito T, Sugiura T, Mori K, Uesaka K: Preoperative neutrophil to lymphocyte ratio and prognostic nutritional index predict overall survival after hepatectomy for hepatocellular carcinoma. World J Surg 39:1501-1509, 2015

23. Paek SH, Audu PB, Sperling MR, Cho J, Andrews DW: Reevaluation of surgery for the treatment of brain metastases: review of 208 patients with single or multiple brain metastases treated at one institution with modern neurosurgical techniques. Neurosurgery 56:1021-1034, 2005

24. Petrie HT, Klassen LW, Kay HD: Inhibition of human cytotoxic T lymphocyte activity in vitro by autologous peripheral blood granulocytes. J Immunol 134:230-234, 1985

25. Satomi A, Murakami S, Ishida K, Mastuki M, Hashimoto T, Sonoda M: Significance of increased neutrophils in patients with advanced colorectal cancer. Acta Oncol 34:69-73, 1995

26. Schackert G, Lindner C, Petschke S, Leimert M, Kirsch M: Retrospective study of 127 surgically treated patients with multiple brain metastases: indication, prognostic factors, and outcome. Acta Neurochir (Wien) 155:379-387, 2013

27. Sharaiha RZ, Halazun KJ, Mirza F, Port JL, Lee PC, Neugut
AI, et al: Elevated preoperative neutrophil:lymphocyte ratio as a predictor of postoperative disease recurrence in esophageal cancer. Ann Surg Oncol 18:3362-3369, 2011

28. Soffietti R, Rudā R, Mutani R: Management of brain metastases. J Neurol 249:1357-1369, 2002

29. Sperduto PW, Chao ST, Sneed PK, Luo X, Suh J, Roberge $\mathrm{D}$, et al: Diagnosis-specific prognostic factors, indexes, and treatment outcomes for patients with newly diagnosed brain metastases: a multi-institutional analysis of 4,259 patients.

Int J Radiat Oncol Biol Phys 77:655-661, 2010

30. Sugiura T, Uesaka K, Kanemoto H, Mizuno T, Okamura Y: Elevated preoperative neutrophil-to-lymphocyte ratio as a predictor of survival after gastroenterostomy in patients with advanced pancreatic adenocarcinoma. Ann Surg Oncol 20:4330-4337, 2013

31. Tendulkar RD, Liu SW, Barnett GH, Vogelbaum MA, Toms $\mathrm{SA}$, Jin T, et al: RPA classification has prognostic significance for surgically resected single brain metastasis. Int $\mathbf{J}$ Radiat Oncol Biol Phys 66:810-817, 2006

32. Teramukai S, Kitano T, Kishida Y, Kawahara M, Kubota K, Komuta K, et al: Pretreatment neutrophil count as an independent prognostic factor in advanced non-small-cell lung cancer: an analysis of Japan Multinational Trial Organisation LC00-03. Eur J Cancer 45:1950-1958, 2009

33. Wesseling P, von Deimling A, Aipape KD: Metastatic tumours of the CNS, in Louis DN, Ohgaki H, Wiestler OD, et al (eds): WHO Classification of Tumours of the Central Nervous System. Lyon: IARC, 2007, pp 248-251

34. Xue TC, Zhang L, Xie XY, Ge NL, Li LX, Zhang BH, et al: Prognostic significance of the neutrophil-to-lymphocyte ratio in primary liver cancer: a meta-analysis. PLoS One 9:e96072, 2014

35. Yamashita J, Ogawa M, Shirakusa T: Free-form neutrophil elastase is an independent marker predicting recurrence in primary breast cancer. J Leukoc Biol 57:375-378, 1995

\section{Disclosures}

The authors report no conflict of interest concerning the materials or methods used in this study or the findings specified in this paper.

\section{Author Contributions}

Conception and design: Mitsuya. Acquisition of data: Mitsuya, Kurakane. Analysis and interpretation of data: all authors. Drafting the article: Mitsuya. Critically revising the article: Mitsuya, Nakasu. Reviewed submitted version of manuscript: all authors. Approved the final version of the manuscript on behalf of all authors: Mitsuya. Statistical analysis: Mitsuya, Kurakane. Administrative/technical/material support: Nakasu. Study supervision: Nakasu, Nozaki.

\section{Correspondence}

Koichi Mitsuya, Division of Neurosurgery, Shizuoka Cancer Center, 1007 Shimo-Nagakubo, Naga-izumi, Sunto, Shizuoka 4118777, Japan.email: k.mitsuya@scchr.jp. 